\title{
A Quarta Dimensão do Instante-Já
}

Marcele Aires Franceschini

UEM

\section{Resumo}

O presente artigo, cujo título faz referência a uma citação de Clarice Lispector em Água Viva (1973), trabalha a questão temporal na obra da autora, levando-se em conta apontamentos da Física Quântica para explicar a dinâmica não linear do tempo, incluindo-se questões da Teoria da Relatividade. Prezou-se relacionar o conceito de quadrimensão, que tanto influenciou os artistas de vanguarda, derrubando-se o valor de tempo-cronológico na literatura. Além de Einstein, Minkowski, Sagan e Hawking, o texto se respalda no tempo de duração interior de Bergson, bem como em concepções de Heidegger. A relação de circularidade também foi levantada, dialogando a obra de Lispector com o quadro "Urutu" (1928), de Tarsila do Amaral.

Palavras-chave: Água viva; quadrimensão; tempo ontológico.

\section{Resumen}

Este artículo, cuyo título hace referencia a Água viva (1973) de Clarice Lispector, trabaja la cuestión temporal en la obra de la autora. Con tal fin, se consideran aportes de la Física Cuántica para explicar la dinámica no lineal del tiempo y se incluyen cuestiones de la Teoría de la Relatividad. También se usa el concepto de cuarta dimensión, que tanto influyó en los artistas de vanguardia, y que conmocionó el valor de tiempo cronológico en literatura. Además de Einstein, Minkowski, Sagan y Hawking, el texto se apoya en el concepto de tiempo de duración interior de Bergson y en concepciones de Heidegger. La relación de circularidad también se plantea a partir del diálogo de la obra de Lispector con el cuadro «Urutu» (1928), de Tarsila do Amaral.

Palabras clave: Água viva; cuarta dimensión; tiempo ontológico. 
1. Pesquisa realizada entre janeiro e junho de 2007.

2. HEIDEGGER, Martin. Ser e tempo, 1989, p. 213.

3. Levando-se em conta que continum aqui significa "o espaço topológico não vazio, separado, conexo e localmente compacto". GRAY, Jeremy; ROWE, David. The Hillbert Challenge, 2000, p. 322 [trad. própria].
"Eu te digo: estou tentando captar a quarta dimensão do instante-jä".

Clarice Lispector

Publicada em 1973 pela editora Artenova, Água viva, de Clarice Lispector, surge como o rebento de duas versões anteriores: uma primeira, datada de julho de 1971, cujo título era Atrás do pensamento: monólogo com a vida; e uma respectiva, Objecto gritante, reunindo textos, fragmentos inéditos e crônicas escritas ao Jornal do Brasil. É, pois, este material disperso, fraturado, a gênese da ficção lispectoriana, que se fortalece na poesia extrema de um texto inclassificável, como a própria autora fez questão de esboçar no original, arquivado na Biblioteca Nacional" "Trata[-se] de um antilivro", escrito "com o menor policiamento possível", ainda que pudesse transparecer a "aparência de fragmentário".

A quarta-dimensão do instante-já fundamenta a relação temporal em Água viva - obra dilacerada, jamais descrita como uma narrativa que se submete a classificações arbitrárias quanto ao gênero e à forma. Utilizam-se, pois, no estudo desta ficção apontamentos da Física Quântica para explicar a dinâmica não linear do tempo, incluindo-se reminiscências da Teoria da Relatividade. Tal aplicação está intrinsecamente relacionada à quadrimensão, ideia que tanto influenciou os artistas de vanguarda, derrubando-se o valor de tempo cronológico na literatura - em especial na prosa moderna, como em Virginia Woolf, Faulkner, Breton, Cortázar, Oswald de Andrade, Mario de Andrade e Guimarães Rosa.

É notório que o ser humano se organiza em três dimensões: comprimento (ou profundidade), largura e altura. A quarta dimensão é ortogonal às outras, isto é: em geometria, perpendicularidade (ou ortogonalidade) impõe-se como a noção que indica se dois objetos - retas ou planos - apresentam um ângulo de $90^{\circ}$. Portanto, ao ultrapassar o conceito euclidiano de tridimensão espacial, a quarta dimensão pode ser identificada como aquela relacionada ao plano do tempo.

Sobre o tópico, Heidegger elucida que dimensão não pode ser pensada como a "circunscrição da possível medição, mas como o alcançar iluminador [...]. O tempo é quadridimensional. O que chamamos de quarta dimensão é o alcançar a que tudo determina"2.

Minkowski, professor de Einstein no início do primeiro decênio do século XX e inspirador de sua teoria espacial entende que os eventos manifestados no espaço (levando- -se em conta a noção de tridimensionalidade) e no tempo (a quarta dimensão) ocorrem separadamente, contudo em um continum ${ }^{3}$ unificado. Em 1908, durante a leitura "Espaço e Tempo", o físico explicou: 
"Henceforth space by itself, and time by itself, are doomed to fade away into mere shadows, and only a kind of union of the two will preserve an independent reality"'.

A partir destes estudos, a Teoria da Relatividade passa a oferecer uma quarta dimensão ${ }^{5}$ temporal, desbancando a ideia de tempo absoluto. Einstein propõe que os eventos no Universo não acontecem em um espaço-tempo separado, porém em uma quarta dimensão intrínseca a tais eventos ${ }^{6}$. Stephen Hawking, em A Brief History of Time, esmiuça a questão: "It is required abandoning the idea that there is a universal quantity called 'time' that all clocks measure. Instead, everyone would have his own personal time"

Em Other Worlds: Space, Superspace and the Quantum Universe, Paul Davies explica que Einstein revolucionou o embate do discurso porque demonstrou que o tempo é "elástico e pode ser expandido ou contraído, dependendo de seu movimento". Deste modo, cada indivíduo carrega um sentido de temporalidade pessoal, já que de acordo com os princípios da Relatividade, sua natureza não é fixa, todavia dinâmica: "It can stretch and shrink, and warp and even stop altogether at a singularity. Clock rates are not absolute, but relative to the state of motion or gravitational situation of the observer"'.

Estas observações resultam no fato de que todos os indivíduos vivem com seu "tempo" personalizado. Davies ainda pondera que "tais momentos, de perspectiva relativa, demonstram-se difíceis de serem capturados em uma narrativa cronológica", sendo "amplamente absorvidos em obras literárias, através do uso da linguagem figurativa, uma vez que o aspecto cronológico não pode ser sempre aplicado de modo holístico". Ele continua sua linha de raciocínio expondo que "as conexões entre o passado, o presente e o futuro relacionam-se e são recursivas - de tal modo que não podem ser facilmente mapeadas em uma linha de tempo plana, horizontal" ${ }^{\prime 10}$.

No âmbito da pessoalidade do tempo, de um lado pode-se citar Einstein com o seu "tempo-eternidade", ligado ao conceito de que "o momento presente dilata-se como a íris quando em contato com a luz"11; e, de outro, Bergson com o seu "tempo-duração", atado à intuição. Ao filósofo, na duração "interna" tudo se modifica continuamente, pois o progresso dos estados psicológicos é "dinâmico": "Se algo se solidifica é porque nos deixamos representar, ilusoriamente, a nós mesmos, como se de fato existíssemos num tempo homogêneo e espacial" ${ }^{12}$.

Em compasso, Água viva tenciona a narrativa em um "tempo pessoal”, tempo de duração emocional; incomensurável. Já no original de Objeto gritante Clarice antecipa o caráter cíclico e infinitamente ecoante do tempo: "Será que tempo é o que dura
4. "De agora em diante, tanto o tempo quanto o espaço estão fadados a desaparecer em meras sombras, e somente a união dos dois poderá preservar uma realidade independente" [trad. própria], apud. NABER, Gregory L. Geometry of Minkowski Spacetime: an Introduction to the Mathematics of the Theory of Relativity, 1992, p. 132.

5. A noção popular de quadrimensão e da dilatação do tempo ganhou atenção especial em 1895, anos antes de Einstein revelar sua teoria da relatividade. Foi quando H. G. Wells publicou seu romance $A$ máquina do tempo. Nesta obra, o protagonista, que viaja para o futuro (oitocentos mil anos), explica a quarta dimensão do tempo em relação às três dimensões euclideanas - obviamente a partir de um campo de visão fictício, com suas limitações científicas. WELLS, H. G. The Time Machine: an Invention, 1992.

6. De acordo com a definição de Sagan, "espaço-tempo" (spacetime) trata-se da estrutura que combina as três dimensões do espaço com a dimensão única do tempo. SAGAN, Carl. Cosmos, 1980, p. 166-167.

7. "É preciso abandonar a ideia de que há uma unidade universal chamada 'tempo', medida por relógios. Ao invés disso, todos teriam o seu tempo pessoal." [trad. própria]. HAWKING, Stephen. A brief history of time: from the big bang to black holes, 1988, p. 98.

8. DAVIES, Paul. Other Worlds: Space, Superspace and the Quantum Universe, 1988, p. 38 [adaptação própria do trecho em inglês].

9. "Ele pode se expandir ou contrair, deformar-se e até mesmo parar em um ponto de singularidade. As unidades de medida do tempo não são absolutas, mas relativas ao estado de movimento ou à situação gravitacional do observador." [trad. própria]. Ibidem, p. 40-41.

10. Ibidem, p. 57-58, respectivamente [adaptações próprias dos trechos em inglês].

11. SAGAN, Carl. Cosmos, 1980, p. 130 [trad. própria].

12. BERGSON, H. Ensaio sobre os dados imediatos da consciência, 1988, p. 64. 
13. LISPECTOR, Clarice. Água viva, 1973, p. 9.

14. BERGSON, H. Ensaio sobre os dados imediatos da consciência, 1988, p. 25.

15. LISPECTOR, Clarice. Água viva, 1973, p. 7.

16. Ibidem, p. 7

17. Cf. NUNES, Benedito. O drama da linguagem: uma leitura de Clarice Lispector, 1995, p. 29.

18. LISPECTOR, Clarice. Água viva, 1973, p. 8.

19. Ibidem, p. 8.

20. "Se todos têm seu tempo pessoal, então o mundo não é baseado em uma causa ordenada ou em uma congruência de efeito, contudo na imersão do presente [...]. Nesta realidade, os artistas são dadivosos. Imprevisível é a manifestação de suas pinturas, músicas ou romances. Simplesmente porque eles se contentam com o inesperado; com os acontecimentos que não demandam explicações ou retrospectivas" [trad. própria]. LIGHTMAN, Alan. Einstein's Dreams, 1993 , p. 37.

21. LISPECTOR, Clarice. Água viva, 1973, p. 19.

22. Ibidem, p. 8.

23. Ibidem, p. 8. para atravessar um espaço? Mas se falo em 'duração', falo de um tempo. E volto ao ponto inicial" ${ }^{\prime 13}$.

Na definição de Bergson, eis "o tempo ontológico por excelência, anterior à trama e à própria consciência, identificado como o Cosmos ou a Natureza" ${ }^{\text {14 }}$. Neste tempo ontológico, alheio ao plano horizontal ou meramente cronológico, o eu-narrador lispectoriano tenta "captar a quarta dimensão do instante-já, que de tão fugidio não é mais"”.

"Instante fugidio" que se engendra na natureza elástica do tempo, pois cada "novo instante-jâ" 16 morre no mesmo segundo em que nasce. Mal ele respira, já se esvai. Nesse compasso, a temporalidade expressa em Agua viva se caracteriza como "ondulante" 17 , articulada à natureza erradia do sujeito-narrador. Mas tal sujeito não desiste. Ele persiste na captura do tempo efêmero, ainda que os instantes decorram "no ar que respiro: em fogos de artifício eles espocam mudos no espaço"18.

Entretanto, à autora não basta a posse do minuto etéreo. Ela ousa em admitir sua ambição de se fixar no "instante-já", fruto do fluxo de pensamento que governa sua escrita: "Quero possuir os átomos do tempo"19. Ao se deparar com o desejo de reter os "átomos" do agora, Lispector trabalha com a perspectiva de tempo não linear, de resistência imediata:

If everyone has their own personal time, then the world is not based on an orderly cause and effect congruency, but one of immersion in the present [...]. In this world, artists are joyous. Unpredictability is the life of their paintings, their music, their novels. They delight in events not forecasted, happenings without explanation, retrospective. ${ }^{20}$

Desde as primeiras linhas, Água viva procura dar espaço ao conceito de tempo ligado à memória involuntária, pressuposto como descontínuo - a duração, em que a ação formal de passado-futuro desaparece totalmente: "É sempre atual, e o fotômetro de uma máquina fotográfica se abre e imediatamente fecha, mas guardando em si o flash. Mesmo que eu diga 'vivi' ou 'viverei', é presente, porque eu os digo já" Lispector inicia seu texto sedenta por captar "a incógnita do instante, duramente cristalina e vibrante no ar" ${ }^{\prime 22}$, pois à mente que escreve a "vida é esse instante incontável" elogio ao "instante", pois muito além de ser matéria central da obra, o "agora" se respalda na vigência do próprio eu-narrador. Escrever e viver tornam-se um só embate:

Mas o instante-já é um pirilampo que acende e apaga, acende e apaga. O presente é o instante em que a roda do automóvel em alta velocidade toca minimamente no chão. $\mathrm{E}$ a parte da roda que ainda não tocou, tocará num imediato que absorve o instante presente e torna-o passado. Eu, 
vivia tremeluzente como os instantes, acendo-me e me apago, acendo e apago, acendo e apago. ${ }^{24}$

Bergson expõe que um fenômeno exterior ocorre ao mesmo tempo em que é percebido interiormente: "Ele modifica os estados da minha consciência, visto que ocorre uma troca entre o espaço exterior e a duração interior. Nenhum momento dura, cada um é instantâneo. O tempo pulveriza-se e o psíquico recomeça a cada instante" ${ }^{25}$.

O instante que o caracteriza é absorvido no ato definitivo da escrita, pois antes mesmo de se apresentar como tempo concreto do relato, este "pirilampo que acende e apaga", este movimento de "roda de automóvel" sempre prestes a tocar o chão, ambos se unificam como "dados imediatos da consciência; tempo interior, imerso no labirinto mental de cada um, apenas cronometrado pelas sensações, ideias, pensamentos e vivências" ${ }^{26}$.

Os lampejos que brotam da consciência criadora da narradora, ao contrário do que possa aparentar, revelam instantes de longa duração, pois através da intuição tanto o leitor quanto o autor são capazes de chegar ao que Leo Spitzer chama de "tempo em estado puro" ${ }^{27}$. Segundo o estudioso, o romancista faz de sua vida interior o motivo para redigir acerca do tempo, retendo a "essência das coisas, a região mais profunda". A ele, a leitura da prosa moderna é complexa devido às "impressões que o tempo deixa em nosso espírito". Nela, "podemos encontrar por trás do efêmero, o eterno; e por trás do particular, o universal" 28 .

Neste cenário, Lispector é a "ficcionista do tempo por excelência" ${ }^{29}$, descrevendo suas impressões - compactadas no minuto transitório - à exaustão. Como resultado de sua experiência, Água viva expõe-se como uma obra de ficção a eleger o instante como mote de criação. A voz narrativa insiste para que a palavra brote no instante criativo, pois o seu "tempo é quanto dura um pensamento" 30 . Todavia, não é com a ação desenfreada de quem escreve por pura libertinagem que a autora se propõe à entrega do instante. Consciente, a voz narrativa assimila que para apreender o que corre com o poder de renovação da água, necessita ser "mais discursiva que o instante", visto que "muitos instantes se passarão antes que desdobre e esgote a complexidade una e rápida de um relance" ${ }^{\prime 31}$.

$\mathrm{Na}$ ânsia de abstrair a substância ínfima do instante - ou do relance -, a escritora percebe que não basta se render ao que se esvai: é preciso comungar do objeto, criando uma ampla teia sensível com os sobressaltos que brotam no momento captado: "E está-se no instante-já: come-se a fruta na sua vigência" 32 . A protagonista agarra a morfologia dos instantes quando deixa a sinestesia conduzir sua narrativa: "Que estou fazendo eu ao te escrever? estou tentando fotografar o perfume"; "E eu aqui me
24. Ibidem, p. 16.

25. BERGSON, H. Ensaio sobre os dados imediatos da consciência, 1988, p. 38.

26. Ibidem, p. 27.

27. SPITZER, Leo. Linguistica e bistória literária, 1968, p. 252.

28. Ibidem, p. 252. [adaptação própria dos trechos em espanhol].

29. MOISÉS, Massaud.

"O Romance", 1979, p. 134.

30. LISPECTOR, Clarice. Água viva, 1973, p. 24.

31. Ibidem, p. 64

32. Ibidem, p. 83. 
33. Ibidem, p. 64 e 13, respectivamente.

34. CIRLOT, Juan E. Dicionário de símbolos, 1969, p. 63.

35. LISPECTOR, Clarice. Água viva, 1973, p. 13.

36. BERGSON, H. Ensaio sobre os dados imediatos da consciência, 1988, p. 27.

37. Ibidem, p. 27.

38. LISPECTOR, Clarice. Água viva, 1973, p. 69.

39. Ibidem, p. 57.

40. MANN, Thomas. $A$ montanha mágica, 1980, p. 541. obrigo à severidade de uma linguagem tensa, obrigo-me à nudez de um esqueleto branco que está livre de humores"33.

Entre os mais distintos elementos presentes em Água viva, Clarice evoca a provocação do perfume - simbologia do aéreo; das lembranças e das reminiscências - e das cores - o branco é a própria cor de deserto (ou o domínio de abstração que se encontra fora do campo vital e existencial, aberto à transcendência $)^{34}$. Ainda além, a escritora confessa sem pudores que se "obriga à nudez do esqueleto branco" 35 , ou seja, à folha de papel, de violência inerte. Eis sua sina diante da criação.

Tais realizações súbitas no ato pleno da escrita contêm o que Bergson chama de "representação da sucessão pura" 36 : "justapomos nossos estados de consciência de maneira a percepcioná-los simultaneamente", seja "comendo da fruta" do iminente, seja "fotografando o perfume" ou confrontando a folha em branco. Aqui não importa como o "instante-já" alerta os sentidos: o primordial é penetrar na carne do instante, de tal modo que "projetamos o tempo no espaço, exprimimos a duração pela extensão, e a sucessão toma para nós a forma de uma cadeia cujas partes se tocam" 37 .

Clarice Lispector consome os lances da faculdade do sentir, permitindo-se à espontaneidade dos gestos, toques, cores e cheiros no acontecimento imediato da narrativa. A autora insiste: ora se entrega ao "êxtase" do "intenso cheiro sagrado" da flor no rompante da ficção ("Mas angélica é perigosa. Tem perfume de capela. Traz êxtase. Lembra a hóstia. Muitos têm vontade de comê-la e encher a boca com o intenso cheiro sagrado" $)^{38}$, ora se põe a escrever febrilmente, ansiosa por captar o tempo: "Segurar passarinho na concha meio fechada da mão é terrível, é como se tivesse os instantes trêmulos na mão"39. No entanto, que de fato ocorre? Lispector busca fazer da palavra o seu próprio alimento - não é simplesmente a questão de se "representar" a realidade, mas a "coisa em si". Ao se aventurar no desejo de "segurar o passarinho", metáfora da retenção dos "instantes trêmulos na mão", a autora interpreta que a vontade escrita "esbate desordenadamente". "Intolerável”, o movimento induz à "mão" uma abertura rápida "para liberar" aquilo que não mais pode ser contido. Eis a peleja da ficcionista: materializar em texto a essência fugidia do que a cerca no tempo da criação.

Thomas Mann, em um trecho de $A$ montanha mágica, lança o desafio: "Pode-se narrar o tempo, o próprio tempo, o tempo como tal e em si?" ${ }^{40}$. A temática do transcorrer cronológico sempre assumiu um papel central na discussão das fronteiras entre a física, a filosofia e a literatura, em especial no século passado, momento em que tanto a ciência quanto a arte enfrentavam rupturas. Enquanto na Suíça Einstein formulava, em 1905, 
a Teoria da Relatividade; dois anos depois Picasso pintava em Paris Les Demoiselles d'Avignon. Intrigado pelo fato de Einstein e Picasso terem produzido trabalhos de grande impacto em fases contemporâneas, Arthur Miller analisa:

A história da ciência e da arte remete aos tempos de Leonardo da Vinci e Galileu, que eram artistas e cientistas. Com o início da ciência moderna, houve uma ruptura entre elas. A arte passou a ser considerada frívola, e a ciência, uma coisa real. Penso que a partir de Einstein e Picasso elas passaram a se unir novamente. As disciplinas básicas cada vez mais se quebravam [...]. Todos estão interessados na interdisciplinaridade e em discutir seus temas de um ponto de vista que possibilite a abertura com a arte. ${ }^{41}$

O tempo da ciência é o tempo da linguagem como construção, que visa um agir. Já o tempo literário é o da duração interiormente vivida. Interpondo a questão, Bakhtin ${ }^{42}$ pondera que o macrocosmo ao qual todo relato pertence está centrado na "cissura" da extensão espaço-temporal instaurada pelas palavras, pelas imagens visuais, pelos sons não verbais, pelos gestos, entre outros elementos. Neste vértice, importa compreender que a presença do cronotopo em Água viva não é meramente cênica. Ela se traduz em uma unidade representativa, induzindo o monólogo a gravitar em torno da indefinição "temporal" (levando-se em conta a definição formal de "tempo" como mera verossimilhança do tique-taque do relógio). A narradora "pinta" sua obra, escrita na plenitude do instante. Eis o seu tempo:

Tente entender o que pinto e o que escrevo agora. Vou explicar: na pintura como na escritura procuro ver estritamente no momento em que vejo - e não ver através da memória de ter visto num instante passado. O instante é este. $\mathrm{O}$ instante é de uma iminência que me tira o fôlego. $\mathrm{O}$ instante é em si mesmo iminente. Ao mesmo tempo que eu o vivo, lanço-me na sua passagem para outro instante. ${ }^{43}$

Nesta passagem a escritora confessa ao leitor seu método de escrita: não escreve apenas "no" instante-já, mas "o" próprio instante-já. Assim como o escultor necessita da matéria-bruta para dar forma à sua obra, a escritora busca o que jorra no ato singular da criação como seu instrumento narrativo. Como a autora afirma, ela já não é mais ludibriada pela "memória", recusando-se aos fatos predeterminados. Lispector trabalha com o que está calcado no "momento-já"; com as vibrações do "agora”. Em carta a Fernando Sabino, ela relata: "Apenas o que é vivo e se mexe me interessa - a vida que simplesmente lateja, pulsa, viceja ou vegeta eu não alcanço mais. Só a ação imediata eu compreendo, e os verbos de movimento" ${ }^{\prime 4}$.
41. MILLER, Arthur. "Einstein e Picasso: mera coincidência", 2006, p. 223-231.

\section{BAKHTIN, M. Questões de literatura e estética: a teoria do} romance, 1998, p. 211-362.

43. LISPECTOR, Clarice. Água viva, 1973, p. 90.

44. SABINO, Fernando (org). Fernando Sabino/Clarice Lispector: cartas perto do coração, 2001, p. 204. 
45. LISPECTOR, Clarice. Água viva, 1973, p. 61.

46. Ibidem, p. 19.

47. "Cada minuto somos outro [...]. Somos tempo e, por sê-lo, nunca acabamos de ser; sempre estamos a ponto de ser" [trad. própria]. PAZ, Octavio. Pasión crítica, 1990, p. 72.

48. HEIDEGGER, Martin. Conferências e escritos filosóficos, 1989, p. 60.

49. Trad. Maria Teresa de Freitas; Rosa Boaventura, 1986, p. 24 e 15 , respectivamente.

50. LISPECTOR, Clarice. Água viva, 1973, p. 13.
A vazão narrativa confere à produção literária clariceana sua qualidade poética, agitando os impulsos das palavras, enérgicas como água de cachoeira, independente de um enredo ou de personagens intermediárias. Livre de "molduras", pode-se classificar Agua viva como um "não romance", situado em um "não tempo", desprovido dos critérios formais da crítica literária passadista. Ou, segundo a crença da narradora, a impossibilidade de se contar com um tempo homogêneo e absoluto reside no fato de que ele, o instante, nunca finda: "Estou neste instante num vazio branco esperando o próximo instante. Contar o tempo é apenas hipótese de trabalho. Mas o que existe é perecível e isto obriga a contar o tempo imutável e permanente. Nunca começou e nunca vai acabar. Nunca" ${ }^{45}$.

O mistério temporal galga pela capacidade de renovação do texto. Há uma circularidade imanente, pois o texto "nunca começou e nunca vai acabar". Origem e fim mesclam-se na obra, daí a "perecibilidade" do tempo. A protagonista ensina: "Eu sou antes, eu sou quase, eu sou nunca" 4 . A repetição sequencial de advérbios só faz reiterar que a única garantia temporal na obra é o aniquilamento do próprio tempo. Bebendo da inquietação que se perpetua no inconsciente do eu-narrador, Lispector não procura, de modo algum, resolver os dados dos conflitos. Ao contrário: eterniza as tensões, pois é só através da não resposta que o leitor se reconhece no tempo autoral. Octavio Paz reflete: a "cada minuto somos otro [...]. Somos tiempo y, por serlo, nunca acabamos de ser; siempre estamos a punto de ser" ${ }^{\text {" }}$.

"A ponto de ser": Heidegger entende que "ser" não é outra coisa que "tempo", na medida em que "tempo" é designado como pré-nome do próprio Ser ${ }^{48}$. Em Arcano 17, Breton acata esta visão de tempo "meditativo"; tempo de vida "instruída", "consciente": "A vida, como liberdade, não se surpreende nem se encanta parcialmente a não ser com o fato de que ela se instrui por si mesma, eleva-se à consciência total dos seus meios e dos recursos [...]. A poesia e a arte terão sempre um fraco por tudo aquilo que transfigura o homem nessa intimação desesperada" ${ }^{\prime 4}$.

Ao se definir o tempo a partir de sua ligação intrínseca com a manifestação individual do ente, conclui-se que sua duração é relativa àquele que cria e àquele que lê: aos olhos que decifram o texto, vinga a tarefa de montar o "quebra-cabeça" que a mente atenta do autor captou no instante ínfimo. A condição de vigência de Água viva está focada, pois, no movimento da voz narrativa, "fixa[ndo] os instantes de metamorfose" ${ }^{50}$ do texto, tais quais fractais que revelam e destroem as mais distintas facetas. No livro, a autora é o próprio rebento da "Super Nova" de sua criação: "[...] divido-me milhares de vezes em tantas vezes quanto os instantes que decorrem, fragmentária que sou"; "Nasci há alguns instantes e estou ficando ofuscada"; "[...] o 
corpo neste instante-já é de grosso cristal facetado e com milhares de faíscas de instantes" ${ }^{51}$.

Em Timaeus, Platão já alerta para a necessidade de fragmentação e movimento, ignorando o tempo cuja ação é linear:

Tanto o passado quanto o futuro são espécies temporais inventadas, as quais inconscientemente transferimos à essência eterna, pois dizemos ele "era", ele "é" e ele "será". No entanto, a verdade é que apenas o "é" se atribui ao tempo, pois tanto o "era" quanto o "será" existem somente no tempo de vigência, uma vez que sofrem deslocamentos [...]. ${ }^{52}$

Este "é" compreendido pelo filósofo corresponde ao que Berta Waldman esboça como a respectiva fusão do tempo da história com o tempo da escrita e da leitura em Água viva: "Daí o esforço da narradora em se fazer entender, porque ela é alguém que, no papel, elabora um texto onde desenha, pinta, esculpe, fotografa uma escritura atemporal" 53 .

No texto, que escoa sem ligação a um passado ou futuro, a "coisa vivida espanta" 54 a presença narrativa. Seu empenho: "trazer o futuro para já”, pois "o futuro é para a frente e para trás e para os lados" "55. Em $A$ arte da fuga em Clarice Lispector, entende-se o argumento da obra: "Passado e futuro só serão chamados para intensificar ainda mais este presente. Ao invés de tornar-se ser da memória, o narrador torna-se o ser do instante" 56 .

$\mathrm{Na}$ vitalidade da escrita, Lispector exercita certo tipo de desprendimento, como um desejo de libertação, "um querer que obriga a voz a se libertar do discurso ordinário, a expectativa de um limiar que se realiza sob o signo do infinito e do eterno" 57 . "Infinito" como uma espécie de "vertigem"58 abstraída pela escrita.

Reflexo do pensamento desde seus manuscritos originais, a experiência do tempo em Água viva dialetiza com princípios da circularidade, indispensavelmente porque o "sempre" e o "nunca" se entrecruzam: "Nunca é o impossível. Gosto de nunca. Também gosto de sempre. Que há entre nunca e sempre que os liga tão indiretamente e intimamente?"59.

Nas palavras de Affonso Romano de Sant'anna, o discurso de Lispector apresenta o ritual de uma "sequência solene", em uma espécie de processo circular, "[...] ajuntando o alto e o baixo num mesmo anelo e aspiração"

Dando-se continuidade à ideia de círculo, de "anelo" no tempo eternizado, Biedermann, em seu Dicionário de símbolos, sintetiza o sempre e o nunca como a serpente enrolada em um ovo, figura comum para os egípcios, os druidas e os indianos. Não é por mero acaso que se lê em Água viva: "O instante é o vasto ovo de vísceras mornas" ${ }^{61}$.
51. Ibidem, p. 8, 49 e 50, respectivamente.

52. PLATÃO. Timaeus, 1963 , p. 133 [adaptação própria da versão em espanhol].

53. WALDMAN, Berta. Clarice Lispector, 1993, p. 61.

54. LISPECTOR, Clarice. Agua viva, 1973, p. 61.

55. Ibidem, p. 33 e 62 , respectivamente.

56. DINIS, Nilson. $A$ arte da fuga em Clarice Lispector, 2001, p. 83.

57. REY, Jean-Michel. O nascimento da poesia, 2002, p. 82.

58. Ibidem, p. 126.

59. LISPECTOR, Clarice. Água viva, 1973 , p. 39.

60. SANT'ANNA, Affonso

Romano de. "O ritual epifânico do texto", apud. LISPECTOR, Clarice. A paixão segundo G.H, 1988, p. 242.

61. LISPECTOR, Clarice. Água viva, 1973 , p. 48. 
62. AMARAL, Tarsila, apud. AMARAL, Aracy. Tarsila: sua obra e seu tempo, 2003, p. 271.
Paralela à frase extremamente aliterante e poética de Água viva, a criação "O ovo", de Tarsila do Amaral (1928), retrata com propriedade a forma rudimentar que caracteriza o início e consequentemente o fim - de tudo. Criada em plena efervescência do Manifesto Antropófago, de Oswald de Andrade, a obra (também conhecida como "Urutu") traz na figura do ovo a gênese; a renovação. A tela $(60 \times 72 \mathrm{~cm})$ faz parte do acervo de Gilberto Chateaubriand, apresentando dimensões hiperbólicas e cores contrastantes:

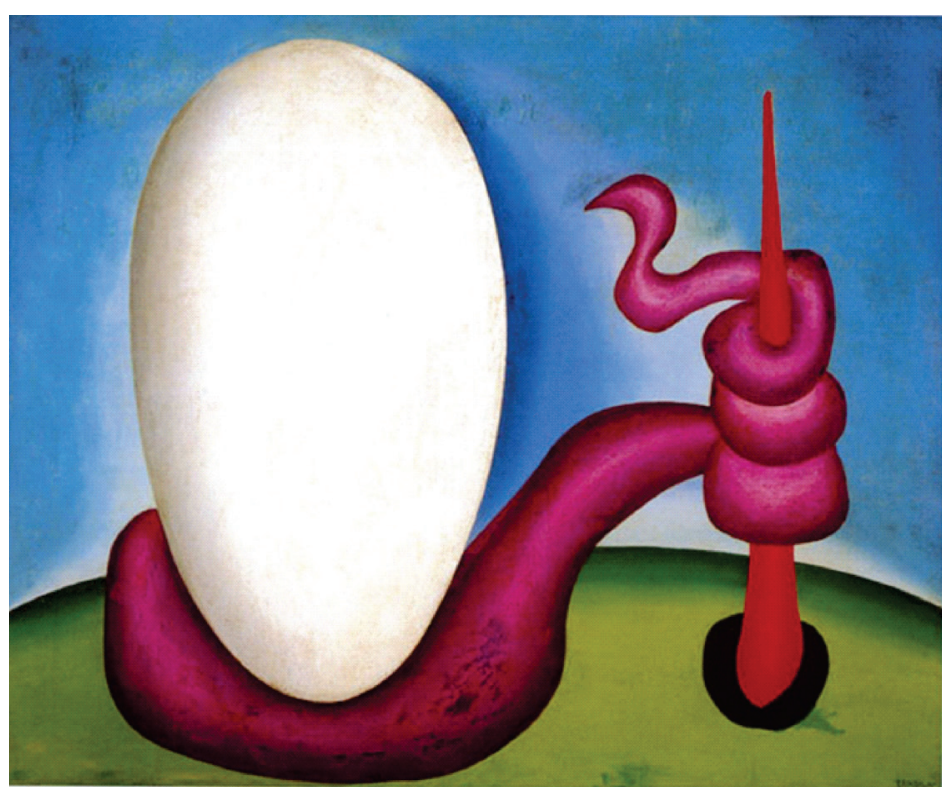

Fig. 01. O ovo (óleo sobre tela - 1928). Galeria Tarsila do Amaral, jan. 2009.

Ao centro um ovo, estratosférico, circundado por uma cobra, enrolada a um mastro. Sua análise estrutural mostra uma distribuição quase simétrica da figura central em relação às linhas medianas, de maneira que o olhar se concentra diretamente na brancura do ovo. Brancura densa, enfatizada ainda mais pelos matizes do azul contrastante ao fundo, do jogo carmim/ rosa da cobra e do verde da base inferior. Em página do catálogo de uma das exposições do Salão de Maio, na década de 1920, Tarsila discorre sobre o cromatismo presente em sua produção:

Encontrei em Minas as cores que adorava em criança. Ensinaram-me que eram feias e caipiras. Segui ao ramerrão do gosto apurado... Mas depois me vinguei da opressão, passando para as minhas telas: azul puríssimo, rosa violáceo, amarelo vivo, verde cantante, tudo em gradações mais ou menos fortes, conforme a mistura do branco. Pintura limpa, sobretudo sem medo de cânones convencionais. ${ }^{62}$

Notadamente, Tarsila é uma das pioneiras na tentativa de abandono às imposições do cânone nas artes modernas no Bra- 
sil. Suas armas são justamente as cores contrastantes e a nitidez de seus contornos. Como não reconhecer a solidez e a assombrosa presença do ovo ${ }^{63}$ Sua brancura imponente revela a despreocupação da pintora em esconder a carnação de sua criação. Em "Urutu" percebe-se, além do branco, o encontro de tons que em nada prejudicam a imanência do ovo. Ao contrário: ressaltam ainda mais a sua presença no espaço. Ou, em compasso ao conto homônimo de Lispector, pode-se dizer que "o ovo é ovo no espaço"; "ovo sobre o azul”"64.

Além da análise cromática, percebe-se que o predomínio das linhas curvas gera uma espécie de representação onírica, acrescentando vitalidade e movimento à pintura. Nesta atmosfera de sonho, o mistério intrigante do ovo representa uma espécie de corredor onde imagens e sensações escapam e retornam continuamente: "O que eu não sei do ovo é o que realmente importa. O que eu não sei do ovo me dá o ovo propriamente dito" ${ }^{\prime \prime}$, pois a Clarice - e concomitantemente a Tarsila - "o ovo é uma exteriorização"; "o ovo expõe"

Com a eventual prevalência da percepção gerada pela exposição do objeto "ovo", as sensações tornam-se a antena pela qual a pintora e a escritora exteriorizam seus conhecimentos e devaneios criativos. Tanto a tela de Tarsila como a ficção de Clarice são objetos que convidam à "viagem" ao "outro lado" ("Será passei sem sentir para o outro lado?”"7), uma vez que a vida reproduzida em frases feitas não passa de uma paisagem-morta. Neste entrave, a forma ultrapassa seu sentido na "grande força do ovo" ${ }^{68}$. É preciso, pois, que a paisagem - descrita/pintada possua resquícios de dureza, ao mesmo tempo em que conserve o paroxismo de uma primitividade selvagem e inocente.

Exprimindo tal natureza abrupta e uterina, Lispector e Tarsila fixam o tema da origem da criação no ovo. O ovo é pai do tempo e as suas infinitas possibilidades de representação estão calcadas no profano anterior ao próprio homem. Quando o ovo surge, a mão tem de se apressar para captar toda sua superfície, de modo que "ver um ovo nunca se mantém no presente", pois mal é visto e "já se torna visto um ovo há três milênios" "9.

Observar os acontecimentos em estado de alerta apresenta-se como uma saída dramática para expressar o posicionamento do ser em um mundo caótico, em total ruptura com o cronotopo e com a ordem formal das análises, em especial no campo das artes. O tempo é destruído no princípio dos sonhos, de maneira que "permanecemos o próprio centro de nossa experiência onírica", pois "os símbolos da noite são comandados pelas formas ovoides"

Paradoxo curioso, é exatamente na origem da "experiência onírica" que Água viva e "Urutu" apreendem a transmutação da massa concreta e real daquilo que nasce de uma "realidade
63. “[...] já pintei um ovo. E agora, como na pintura, só digo: ovo e basta". LISPECTOR, Clarice. Agua viva, 1973, p. 95.

64. Idem. A legião estrangeira, 1988 , p. 82.

65. Ibidem, p. 82.

66. Ibidem, p. 82.

67. Idem. Água viva, 1973, p. 21.

68. Idem. A legião estrangeira, 1988, p. 82.

69. Ibidem, p. 82.

70. BACHELARD, Gaston.

$O$ direito de sonhar, 1986, p. 161-62, respectivamente. 
71. LISPECTOR, Clarice. Água viva, 1973, p. 22.

72. Ibidem, p. 15.

73. BACHELARD, Gaston. O direito de sonhar, 1986, p. 184.

74. NIETZSCHE, Friedrich. A gaia ciência, 1981, p. 47.

75. LISPECTOR, Clarice. Agua viva, 1973, p. 28 e 11, respectivamente. delicadíssima": "Não, isto tudo não acontece em fatos reais, mas sim no domínio de - de uma arte? sim, de um artifício por meio do qual surge uma realidade delicadíssima que passa a existir em mim: a transfiguração me aconteceu" "71.

O outro lado da moeda é o estado de latência que domina os autores de um mundo em ebulição interior. Assim, se a tentativa incompleta da palavra e do traço gera o delírio, o corpo, inevitavelmente, torna-se veículo do sonho, invólucro da inspiração:

Tudo é pesado de sonho quando pinto uma gruta ou te escrevo sobre ela - de fora dela vem o tropel de dezenas de cavalos soltos a patearem com cascos secos as trevas, e do atrito dos cascos o júbilo se liberta em centelhas: eis-me, eu e a gruta, no tempo que nos apodrecerá. ${ }^{72}$

Eis a imagem perfeita do ciclo caótico de uma vida: o ser primário em liberdade, "solto a patear com cascos secos as trevas". Ser engendrado de um "útero-gruta", espaço dos "tropéis", onde há o nascimento e o consequente "apodrecimento" daquilo que vingou como fruto maduro. Igualmente, apelando para o grotesco, Tarsila aposta no exagero não apenas para reproduzir o monstruoso, o sublime, mas para extrapolar os limites de representação formal. A fim de construir e atar ao caos da criação suas infinitas intuições, tanto a pintora quanto a escritora aniquilam a continuidade encadeada do tempo. Sobretudo porque o instante poético é de natureza quadrimensional: provoca, emociona, afronta, espanta, convida e revigora no segundo flexível. No mínimo, "o instante poético é a consciência de uma ambivalência. Porém é mais: é uma ambivalência excitada, ativa, dinâmica"73.

Assim como o movimento espiral indica evolução, reconstrução, Água viva e "O Ovo" evocam um eterno retorno, ou a "ampulheta da existência sempre virada outra vez" ${ }^{74}$, como infere Nietzsche no aforismo 341 de $A$ gaia ciência. Substancialmente porque nas obras há um irrequieto questionamento sobre o tempo, indicando que sua exposição não se faz em polos opostos e inconciliáveis, mas em estilhaços de uma múltipla face. Logo, "sempre" e "nunca" são instâncias complementares de uma mesma realidade: "Minha pequena cabeça tão limitada estala ao pensar em alguma coisa que não começa e não termina - porque assim é o eterno"; "Não pinto ideias, pinto o mais inatingível 'para sempre'. Ou 'para nunca', é o mesmo"75.

Considerando-se o tempo infinito e o jogo de forças nele contido, a alternância nunca acaba, "porque assim é o eterno". $\mathrm{Na}$ Teogonia, as Musas não nascem antes, depois nem simultaneamente com Zeus. Para que ocorra uma dessas três possibilidades, é necessário que irrompa um tempo absoluto, preexistente 
por si $\mathrm{mesmo}^{76}$. Contudo, ao contrário do tempo mitológico, em que o decurso homogêneo é cercado por acontecimentos que não o podem afetar, Lispector busca na "quarta dimensão do instante-já" um incansável contraponto, pois a menor fração do momento contempla a inquietação construtiva: "[...] fixo os instantes de metamorfose e é de terrível beleza a sua sequência e concomitância" "77.

A autora não se delimita à presença numinosa ${ }^{78}$ do eu-narrador. Sua escrita opera com o tempo expelido, como os relógios derretidos de Dali em "A persistência da memória" (1931) e o relógio sem ponteiros de Bergman em "Morangos silvestres" (1957). Todos os caminhos levam à impossibilidade de se pensar Água viva como a configuração de uma temporalidade sucessiva, abrangendo um antes e um depois. Dentro do contexto do sagrado na Teogonia, "anterioridade" e "posterioridade" são noções rigorosamente excludentes uma da outra ${ }^{79}$. E a obra de Lispector, ao contrário, não pretende apurar uma coincidência de contrários, mas sim de uma percepção e concepção do tempo tal que cesse estas duas noções. O papel da escritora/pintora é trabalhar com o fenômeno temporal, tomando a precaução de refletir antes de olhar seu objeto de escrita/pintura: "Ouço o ribombo oco do tempo"; "A palavra "perpétua" não existe porque não existe o tempo? Mas existe o ribombo. E a existência minha começa a existir. Começa então o tempo?" ${ }^{\prime \prime}$.

A quarta-dimensão do instante pleno em Água viva é da mesma essência do que instaura o instante poético - o tempo e sua multiplicidade. É esse o tempo que a autora aceita ao dispensar a formalidade cronológica do romance de tradição. A escolha pelo caos assegura que toda e qualquer horizontalidade "achatada" ${ }^{11}$ se retraia e o tempo não mais delimite linhas de duração. Na obra o tempo extravasa; jorra no "instante-já".

Começa então o tempo na cauda da serpente, pois, como pensa Mallarmé: "um livro não começa, nem acaba"82. Ou, nas palavras da própria Lispector: "O que estou te escrevendo não é para se ler é - para ser" ${ }^{\prime 83}$.

A autora é enfática: sua composição não foi criada para a "leitura", mas para a "vivência". Afinal, "ser" é o verbo primário da narrativa e do próprio ato de abandono ao tempo preso nas arestas do "real". Adiante, em Um sopro de vida, a temática é retomada na seguinte conclusão: "O tempo não existe. O que chamamos de tempo é o movimento de evolução das coisas, mas o tempo em si não existe. Ou existe imutável e nele nos transladamos" $"$.

"Transladar-se" soa como uma excelente definição à essencialidade temporal da ficção de Clarice. Ela, a autora que bebe das "águas abundantes" 85 de uma fonte que jamais seca. Daí seu
76. HESÍODO. Teogonia: a origem dos deuses, 1989, p. 103.

77. LISPECTOR, Clarice. Água viva, 1973, p. 13.

78. Nume é relativo ao Nome, ou à Presença Sagrada na narrativa (idem). Rudolf Otto, em The Idea of the Holy (1920) esclarece que o termo "numinoso" evoca sentimentos antigos e arraigados no inconsciente coletivo, colocando o ser frente àquilo que é divino. Em contraposição, pode-se dizer que Clarice captura para o mundo aquilo que, "divinamente”, é do homem.

79. HESÍODO. Teogonia: a origem dos deuses, 1989, p. 109.

80. LISPECTOR, Clarice. Agua viva, 1973, p. 42.

81. BACHELARD, Gaston.

"O instante poético e metafísico".

Em: O direito de sonhar, 1986, p. 185.

\section{MARINETTI, F.T.}

"Supplément au Manifeste technique de la littérature futuriste", apud. ARANHA, Graça (org). Futurismo (Manifesto de Marinetti e seus companheiros), 1926.

83. LISPECTOR, Clarice. Água viva, 1973, p. 42.

84. Idem. Um sopro de vida: Pulsações, 1978, p. 5.

85. Idem. Água viva, 1973, p. 33. 
86. Idem. Um sopro de vida: Pulsações, 1978, p. 7. destino maior: "Eu não faço literatura: eu apenas vivo ao correr do tempo. O resultado fatal de eu viver é o ato de escrever" ${ }^{\prime 86}$.

\section{Referências}

AMARAL, Aracy. Tarsila: sua obra e seu tempo. São Paulo: Ed. 34/Edusp, 2003.

BACHELARD, Gaston. O direito de sonbar. Tradução de José Américo Motta Pessanha. São Paulo: Difel, 1986.

BAKHTIN, Mikhail. Questões de literatura e estética: a teoria do romance. Tradução de Aurora Bernardini. São Paulo: Ed. UNESP/Hucitec, 1998.

BERGSON, H. Ensaio sobre os dados imediatos da consciência. Tradução de J. Gama. Lisboa: Edições 70, 1988.

CIRLOT, Juan Eduardo. Dicionário de simbolos. Barcelona: Labor, 1969.

DAVIES, Paul. Other Worlds: Space, Superspace and the Quantum Universe. New York: Penguin Books, 1988.

DINIS, Nilson. $A$ arte da fuga em Clarice Lispector. Londrina: Eduel, 2001.

GRAY, Jeremy; ROWE, David. The Hillbert Challenge. London: Oxford Unity Press, 2000.

HAWKING, Stephen. A brief history of time: from the big bang to black boles. New York: Bantam Books, 1988.

HEIDEGGER, Martin. "Ser e tempo". In:

Conferências e escritos filosóficos. Tradução e notas de Ernildo Stein. São Paulo: Nova Cultural, 1989.

HESÍODO. Teogonia: a origem dos deuses. Tradução e estudo de Jaa Torrano. São Paulo: Roswitha Kempf, 1980.

LIGHTMAN, Alan. Einstein's Dreams. New York: Warner Books, 1993.

LISPECTOR, Clarice. Água viva. Rio de Janeiro: Editora Artenova, 1973. "O ovo e a galinha". In: São Paulo: Ática, 1988. A legião estrangeira. Um sopro de vida: Pulsações. Rio de Janeiro: Nova

Fronteira, 1978. 
MANN, Thomas. A montanha mágica. Tradução de Herbert Caro. Rio de Janeiro: Nova Fronteira, 1980.

MARINETTI, F. T. "Supplément au Manifeste technique de la littérature futuriste”. In: ARANHA, Graça (Org.). Futurismo (Manifesto de Marinetti e seus companbeiros). Rio de Janeiro:

Pimenta Melo, 1926.

MOISÉS, Massaud. “O Romance”. In: A criação literária. São Paulo: Melhoramentos, 1979.

MILLER, Arthur. "Einstein e Picasso: mera coincidência?". Revista de História, Ciências, Saúde - Manguinhos, v. 13 (suplemento), p. 223-31, outubro 2006.

NABER, Gregory L. Geometry of Minkowski Spacetime: an Introduction to the Mathematics of the Theory of Relativity. New York: Springer, 1992.

NIETZSCHE, Friedrich. A gaia ciência. Tradução de Marcio Pugliesi. São Paulo: Hemus, 1981.

NUNES, Benedito. O drama da linguagem: uma leitura de Clarice Lispector. São Paulo: Ática, 1995.

OTTO, Rudolf. The Idea of the Holy. Tradução de John Harvey. New York: Oxford University Press, 1920.

PAZ, Octavio. Pasión crítica. Prólogo y notas de Hugo Verani. Barcelona: Seix Barral, 1990.

PLATÃO. Timaeus. Tradução do grego, prólogo e notas por Francisco de P. Samaranch. Buenos Aires: Aguilar, 1963.

REY, Jean-Michel. "A versão poética”. In:

O nascimento da poesia: Antonin Artaud. Belo Horizonte: Autêntica, 2002.

SABINO, Fernando (Org.). Fernando Sabino/Clarice Lispector: cartas perto do coração. Rio de Janeiro: Record, 2001.

SAGAN, Carl. Cosmos. New York: Ballantine, 1980.

SANT'ANNA, Affonso Romano de. "O ritual epifânico do texto”. In: LISPECTOR, Clarice. A paixão segundo G.H. Ed. crítica Benedito Nunes (coord.). Paris: Association Archives de la littérature latino-américaine, des Caraibes et africaine du XXe siècle; Brasília: CNPQ, 1988.

SPITZER, Leo. Linguística e história literária. Tradução de José Riesgo. Madrid: El Gredos, 1968.

WALDMAN, Berta. Clarice Lispector. São Paulo: Brasiliense, 1993.

WELLS, H. G. The Time Machine: an Invention. New York: Tor Book, 1992. 
